Daimon. Revista Internacional de Filosofía, Suplemento 5 (2016), 563-569

ISSN: 1130-0507 (papel) y 1989-4651 (electrónico)

http://dx.doi.org/10.6018/daimon/270141

\title{
El cuerpo humano y éste su mundo
}

\author{
The human body and his world
}

\author{
MIRTA ALA VARGAS PÉREZ*
}

\begin{abstract}
Resumen: Una de las características del ser humano en la sociedad contemporánea es el creciente culto al cuerpo, dando con ello una serie de modificaciones que van desde someter el cuerpo a través de dietas y ejercicios hasta recurrir a cirugías "estéticas" con el fin de tener un cuerpo ideal, acorde a los ideales de belleza que responden a una sociedad de consumo. El siguiente escrito tiene como finalidad abrir un espacio de discusión a partir de la mercantilización que se ha llevado a cabo del cuerpo humano, generando nuevos estilos de vida que producen un narcicismo exacerbado, bajo el esquema de mantenerse siempre joven, con ello negando la finitud humana.

Palabras clave: Cuerpo, moda, posmodernidad, cirugía estética.
\end{abstract}

\begin{abstract}
One aspect of human beings in contemporary society, is the overemphasis cult of the body , thereby giving a series of amendments ranging from submit to the body through diet and exercise to appeal and the " cosmetic " surgeries in order to have an ideal body, ideals of beauty respond to a consumer society. These paper It aims to contribute to the discussion of why, how and when the body become an object of consumption, creating new lifestyles that produce an exacerbated narcissism, under the scheme of keep forever young, thereby denying the human finitude.
\end{abstract}

Keywords: Body, fashion, postmodernism, plastic surgery.

Tarde o temprano el tiempo surge de nuevo, inexorablemente, porque no hay remedio humano posible contra el tiempo, o al menos no lo conocemos. Entonces los amantes descubren que aunque en la caricia el tiempo no cuenta, Kronos regresará, interrumpirá el beso con su fuerza y les recordará que son seres finitos, frágiles y vulnerables, les recordará que viven a merced del cambio y de la transformación, de la caducidad y de la muerte.

Mèlich $(2012,137)$.

Fecha de recepción: 11/06/2016. Fecha de aceptación: 06/09/2016.

* Contacto: tarim1010@gmail.com Mirta Ala Vargas Pérez, Licenciada en Ciencias de la Educación por la Universidad Autónoma de Tlaxcala, México. Ha impartido cursos de formación docente en la Universidad Autónoma de Tlaxcala, México. (2012-2013), dictaminadora de ponencias en el congreso internacional de educación 2012 y 2015, organizadora del XIX encuentro regional de estudiantes y pasantes de filosofía con sede en Puebla (2014), egresada de la maestría en Filosofía de la Benemérita Universidad Autónoma de Puebla. 
Hablar del cuerpo en tanto se es cuerpo en una época como la que se tiene resulta complicado ya que el converge en un universo de significados, así la principal pregunta sería ¿a qué nos referimos cuando hablamos de cuerpo? ¿Qué es esto que llamo cuerpo mío? ¿Hasta qué punto se puede decir que es mi cuerpo y que decido sobre él sin que en ésta decisión se encuentren factores externos o bien discursos, construidos sobre lo que es o debe ser mi cuerpo? Es de más mencionar el desapego que la tradición filosófica ha tenido en relación al cuerpo, ya que él sólo ha representado la envoltura de algo que tiene que ser liberado. El cuerpo ha sido considerado motivo de pecado como lo fue en la tradición cristiana, había que eliminar las tentaciones de la carne puesto que ellas corromperían el alma.

A partir del renacimiento el cuerpo es visto como expresión de su creador, es decir somos hechos a imagen y semejanza de Dios por lo tanto el cuerpo es una manifestación de un poder de creación que puede mostrarse para ser admirado. A partir de entonces es que se empieza a tener un cuidado por el cuerpo con la finalidad de conservarlo.

Habrá que construir el simbolismo y significado de éste cuerpo que aparece en un mundo de la mercadotecnia, con spots que sugieren la compra y venta de productos con los que se alcanzará una felicidad momentánea, de qué forma no alcanzar lo efímero sí las situaciones, sociales, políticas y económicas provocan un malestar en las situaciones vitales de los seres humanos. Hoy tenemos más frustraciones, estrés, miedos, melancolías, incertidumbres y depresiones por la complejidad del siglo XXI.

El cuerpo humano tal como surge a partir del acontecimiento nacer, es un cuerpo no sólo con funciones biológicas, es un cuerpo que es vivenciado por el ser, por un ser finito que se reconoce sarx, con impulsos, deseos, emociones, hambre, frio, sueño, enfermedades, esta condición es la que permite percibir el cuerpo, mi cuerpo que se espacia en el mundo, que es portador de sentido, de significados, portador de poder y de discursos elaborados en diferentes situaciones históricas y que puede revisarse ampliamente en Foucault.

El cuerpo de este tiempo, es un cuerpo a la carta, al servicio de la globalización corporal, un ida y vuelta de información saturada en esquemas idealistas, en modas, una apertura de puentes geográficos que muestra al cuerpo del otro un producto de adquisición al mejor postor, el consumo de un mundo cuyo eje principal es producir y con ello aportar a la sociedad del conocimiento, y si se puede producir "conocimiento" sobre el cuerpo que mejor. "La regulación de los cuerpos en nuestra sociedad es la de una sociedad de consumo, se nos incita a consumir: alimentación, sexualidad, cuidado estético y ejercicio físico, la cultura de la salud nos arrastra con su cuidado y con su anomalía" (Constante, 2014, 200).

No solo existe una regulación sino una normalización hacia el mito de la eterna juventud, pero esta normalización es aún más sutil, tanto, que es casi imposible identificarla, ya que opera bajo la estructura de dar libertad de elección a los individuos, de abrir nuevos horizontes de sensibilidad para mostrar un cuerpo que lo puede todo. Los dispositivos de control se encargan de interiorizar una filosofía de lo esbelto, lo ultra delgado, la talla 0 y doble 00. "El cuerpo esbelto no es sólo un ideal estético, es además una idea moral, un principio de normalización. El sujeto delgado es un sujeto auto-disciplinado" (Medina, 1996, 107). 


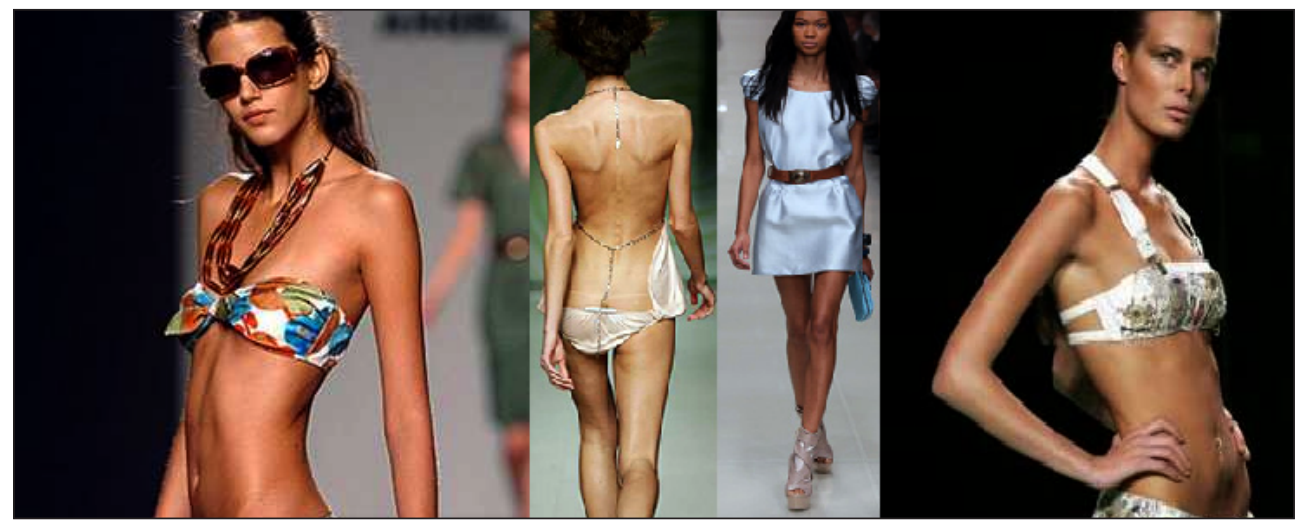

Los cuerpos jóvenes despiertan pasiones, deseos, principalmente hacia el ámbito sexual con el que opera nuestra sociedad actual, los cuerpos, delgados, firmes son los que venden en las páginas de pornografía, en los aparadores de moda, en las revistas de dietas y de sociales, en los comerciales de celulares, perfumes, autos, dulces, dentales, etc.

El poder que se ejerce sobre el cuerpo y que el cuerpo mismo ejerce como productor de deseo se convierte en un dispositivo de poder por el cual se lleva a cabo una biopolítica en los seres humanos de este siglo.

En este sentido el cuerpo, este que percibo, que palpo, que padezco y en cuyo aparecer se delata mío, se da en un mundo de significaciones con la implicación primera que tal como lo estoy percibiendo choca con el mundo dado, el cuerpo entonces se sumerge en el mundo teniéndolo que habitar, pero el mundo no aparece en tabula rasa, el mundo es una ventana virtual a la percepción de los cuerpos dando a estos una serie de atención que antes no se dio.

Si bien es cierto que en la tradición filosófica no se tematiza sobre el cuerpo en tanto se es cuerpo, ahora se ha caído indica Martínez $(2004,132)$, en una "cultura somatica" donde el cuerpo es el principal centro de atención, pero una atención hacia el esteticismo, por lo tanto, mantener el cuerpo se vuelve una de las claves principales, con dietas bajas en calorías, no se sostiene que el cuidado de si no se tome en cuenta, lo que se indica es que detrás de este letrero "cuidado" hay una industria de producción como son: fármacos (tabletas, cremas, ungüentos, inyecciones), suplementos alimenticios, estos formando cadenas alrededor del mundo que operan bajo los esquemas de programación neurolingüística, comidas light, naturales, equipo para ejercicio, cursos de rutinas para adelgazar, libros, terapias de autoayuda, ropa para disimular el sobrepeso y una gran producción de imágenes publicitarias con cuerpos delgados en donde a mercadotecnia ha encontrado su auge. "El cuidado del cuerpo no hace referencia sólo a la salud, sino también a sentirse bien; nuestra felicidad y realización personal, cada vez más, están sujetas al grado en que nuestros cuerpos se ajustan a las normas contemporáneas de salud y belleza" (Martinez, 2004,140).

Con ello se ha dado como resultado un aumento de más del $200 \%$ en cirugías estéticas, desde el 2000, los estiramientos de piel registraron un incremento del 180 por ciento y las abdominoplastias un 165 por ciento. En 2013, se realizaron más de 23 millones de intervenciones estéticas quirúrgicas y no quirúrgicas, según estadísticas difundidas por la 
Sociedad Internacional de Cirugía Plástica Estética, asociación internacional líder de cirugía estética con más de 2.700 cirujanos certificados miembros de 95 países. Como se muestra en su informe disponible en http://www.isaps.org/Media/Default/globalstatistics/2014\%20 ISAPS\%20Global\%20Stat\%20Results.pdf (consultada el 20 de feb del 2015).

\section{TENDENCIAS EN CIRUGÍA PLÁSTICA}

\begin{tabular}{|c|c|c|}
\hline $\begin{array}{l}\text { Estos fueron los países en los } \\
\text { que se realizaron la mayor } \\
\text { cantidad de intervenciones } \\
\text { estéticas quirúrgicas y no } \\
\text { quirúrgicas durante 2013: }\end{array}$ & $\begin{array}{l}\text { Estas fueron las principa- } \\
\text { les intervenciones estéticas } \\
\text { quirúrgicas realizadas en } \\
\text { 2013: } \\
\text { - Aumento mamario } \\
\text { (1.773.584) } \\
\text { - Liposucción (1.614.031) } \\
\text { - Blefaroplastia (1.379.263) } \\
\text { - Lipoestructura incluidos } \\
\text { lipoinjertos estándares } \\
\text { y mejorados con células } \\
\text { (1.053.890) } \\
\text { - Rinoplastia (954.423) }\end{array}$ & $\begin{array}{l}\text { Los principales procedi- } \\
\text { mientos no quirúrgicos fue- } \\
\text { ron los siguientes: } \\
\text { - Toxina botulínica } \\
(5.145 .189) \\
\text { - Rellenos y reabsorbibles } \\
(3.089 .686) \\
\text { - Eliminación capilar por } \\
\text { láser (1.440.252) } \\
\text { - Rejuvenecimiento facial } \\
\text { no invasivo (1.307.300) } \\
\text { - Peeling, láser fraccionado } \\
\mathrm{CO}_{2}, \text { dermoabrasión } \\
(773.442)\end{array}$ \\
\hline $\begin{array}{l}\cdot \text { Estados Unidos: } \\
\text { 3.996.631 (17\%) } \\
\cdot \text { Brasil: } 2.141 .257(9,1 \%) \\
\text { · } \text { México: } 884.353(3,8 \%) \\
\cdot \text { Alemania: } 654.115 \\
(2,8 \%) \\
\cdot \text { España: } 447.177(1,9 \%)\end{array}$ & $\begin{array}{l}\text { Las mujeres se sometieron } \\
\text { a más de } 20 \text { millones de } \\
\text { procedimientos estéticos, lo } \\
\text { que representa un } \mathbf{8 7 , 2} \% \\
\text { del total. Las intervenciones } \\
\text { quirúrgicas más comunes en } \\
\text { mujeres durante } 2013 \text { fueron } \\
\text { las siguientes: } \\
\text { - Aumento mamario } \\
\text { - Liposucción } \\
\text { - Blefaroplastia } \\
\text { (rejuvenecer parpados) } \\
\text { - Lipoestructura (aportar } \\
\text { volumen) } \\
\text { - Levantamiento mamario }\end{array}$ & $\begin{array}{l}\text { Los hombres se sometieron } \\
\text { a más de } 3 \text { millones de } \\
\text { procedimientos estéticos, lo } \\
\text { que representa un } \mathbf{1 2 , 8} \% \\
\text { del total. Las intervenciones } \\
\text { quirúrgicas más comunes } \\
\text { en hombres durante } 2013 \\
\text { fueron las siguientes: } \\
\text { - Rinoplastia } \\
\text { - Reducción de pechos por } \\
\text { ginecomastia } \\
\text { - Blefaroplastia } \\
\text { - Liposucción } \\
\text { - Otoplastia (deformidades } \\
\text { de orejas) }\end{array}$ \\
\hline
\end{tabular}

Realizado a partir del informe 2013 completo de las estadísticas de la ISAPS.

Al cuerpo de hoy, este su mundo que se le presenta extraño, ajeno, ante una mercadotecnia que lo avasalla, pide lo que quieras y se te dará decía un viejo proverbio, 
el acontecer del cuerpo en el siglo XXI es promovido por un eje motor narcisista que instaura una idea de belleza eterna, de la no caducidad, esta idea del no envejecer ha dado como resultado una serie de prácticas desarrollada en el cuerpo humano, un cuerpo que se subjetiva ante los discursos del mercado, discursos que encuentran su forma en la reproducción de maniquís "ideales".

Para el cuerpo, gracias al auge de la ciencia y la tecnología se han desarrollado nuevas técnicas para incidir en él, que van desde las tópicas hasta las quirúrgicas, otras más recientes como las llamadas "no invasivas" se les llama no invasivas aquellas que no se llevan a cabo mediante un procedimiento violento es decir, que no se requiere abrir mediante un bisturí. Lo no invasivo no implica una no alteración en el cuerpo, no implica aparezca un extraño, lo llamado no invasivo se convierte en invasión al modificar la estructura del cuerpo para mantener la ilusión de la juventud eterna; lo no invasivo se convierte en un discurso de la medicina estética, en los juegos del poder que se instaura en un saber de la profesión.

¿Cómo puede hablarse entonces del cuerpo, si el cuerpo esta intervenido? si se dice que es mi cuerpo porque lo percibo mío en cada una de sus latencias, cuando hay algo que se incorpora al cuerpo o que se quita, entonces estos agentes son extraños, ya no representan mi cuerpo, puesto que hay otro espacio haciendo espacio dentro del mío, y este extraño que se espacia en mi cuerpo, no es el de otra vida sino de una sustancia inerte y desechable que ahora se amolda a mí cuerpo haciendo que el cuerpo se convierta un hibrido, en un cyborg. Eso es lo que ha dejado la tecnología, la muestra de que el hombre es capaz de implantar nuevos formas en su cuerpo que se incorporan a un mundo diseñado.

Entonces el cuerpo ya no es mío, he creado un símbolo he signado mi cuerpo, ¿para qué? o ¿para quién? Están dos cuestiones podrían responder a enaltecer el ser que en su existencia se descubre insatisfecha, acostumbrado a modificar y controlar su entorno y claro no podía dejar de hacerlo también en su cuerpo, pues este en su existencia caduca se enfrenta a los estragos corporales de una mercadotecnia que lo satura con el photoshop de un cuerpo joven, musculoso, delgado, sexualmente deseable, en el ser humano Duch y Mèlich $(2005,19)$, dirán que "su existencia se encuentra en los límites y posibilidades de una cultura concreta de un mundo que es ya un mundo construido y normalizado".

Si aceptamos lo anterior entonces justificamos que la cultura actual manda el tipo de individuos aceptables y se deniega toda posibilidad de creación, pero también concretamos en base a Foucault que existe una normalización en el discurso que se interioriza en las diferentes formas de vida, en este caso en una sociedad globalizada y empoderada por la imagen que se interioriza en el hombre.

A lo anterior decimos que, el ser humano es un ser que siempre está en falta, carente y por lo tanto ausente, que existe "un deseo de ser otro, de ser alguien distinto, de ser diferente y que este deseo es siempre un deseo insatisfecho" Mèlich (2002), aún existe un deseo metafísico de lo inmutable en nuestra sociedad y, se refleja en el culto al cuerpo, no hemos aceptado que nuestra vida es demasiado corta, que el momento del apogeo, de la juventud, de la fuerza, del ímpetu es sólo momentáneo, que la carne envejece y deja de producir, que cada latido es uno menos, la negativa a aceptarlo es nuestro aferrarse a un no fluir de los días que se viven, por ello se desea el cuerpo sin caducidad y un cuerpo que enaltezca los ideales de una cultura que excita con su propuesta de belleza y deseo sexual. 


\section{Educación, finitud, cuerpo}

Aprender que lo contingente es lo indisponible de la existencia humana es un tema que podría abordarse en la educación, ¿por qué en las aulas escolares no se toca ese tema, será acaso que en la escuela seguimos educando bajo una visión metafísica?

En la educación, no se educa para la muerte, para soportar la ausencia del otro, de la persona amada, no hay nada que de consuelo ante tal situación, nunca se habla de que un día tarde o temprano el corazón dejará de latir y caeremos a la sombra del olvido.

Puesto que la finitud es una condición del ser humano, constantemente con enfrentamos a ellas, en nuestra existencia la muerte es una presencia constante que nos acecha, que amenaza con irrumpir el espacio que habitamos. ¿Qué pasa cuando a un estudiante de cualquier edad tiene que enfrentarse a la muerte del otro, de un amigo, pareja sentimental, abuelo, padre, mascota? ¿De qué manera se escucha al otro ante la pregunta por qué se murió?

Hemos dejado de lado que en un proceso educativo el otro, en este caso el estudiante llega a las aulas con una historia de vida, con sus sueños e inquietudes y que eso impacta directamente en el proceso educativo de una escuela, en la relación educativa nos encontramos de cara abiertos a historias de vida con diferentes experiencias en sí mismas y en ellas puede existir la ausencia del otro en esa historia.

Si la vida es todo lo que nos acontece en tanto ella existe, la muerte es parte de la vida, uno de los fundamentos de la educación integral es formar para la vida, de igual forma se dirá en formar competencias para la vida, la vida es también muerte, morimos lentamente a medida que avanza el día, cada día, cada hora es un momento menos en nuestra existencia, una educación que se diga integral hablaría de los aspectos contingentes de la vida ${ }^{1}$, una educación que se diga de calidad hablaría también de calidad de vida.

Cuando hablamos de calidad de vida lo referiremos desde un sentido bioético en el cual hay que dar una determinada de respuesta sobre cómo enfrentar la muerte del otro, cuando esta muerte es decisión del que se encuentra enfermo o cuando esta muerte es decisión de un médico, siguiendo con el párrafo anterior ¿cómo se enfrenta la muerte? Cuando un estudiante dice desconectaron a mi papá, murió de cáncer mi abuela o más aún murió siendo víctima de secuestro.

Considero que una educación para un tiempo como en el que vivimos, habrá que dar cuenta de la finitud humana, una finitud que representa posibilidad de creación, un posibilidad de estar en el mundo y con el mundo, una posibilidad de estar con los otros, puesto que es con el otro donde cabe una posibilidad para la ética, para abrir mi espacio y permitir que entre el otro, para dar paso al surgimiento del otro.

Suponemos que en un curriculum operativo como el que se plantea en el siglo XXI, hablar de la muerte no es significativo porque ello sería una ruptura con la metafísica del mundo científico-tecnológico en el cual como se mencionó en las páginas anteriores se prioriza la eterna juventud. Y en una educación tecnológica es muy importante innovar en el cuerpo para que éste sea intervenido.

1 De no abordar el tema de la muerte continuaríamos en una idea metafísica que da privilegio al no fluir del tiempo, una metafísica que amenaza con encasillarlo todo y tener la última respuesta que se diga verdadera. 
Por tal sentido, consideramos que en la educación es importante tocar el tema de la muerte, porque esto nos lleva a un proceso de interiorización sobre nuestra vida finita y el replanteamiento de las intervenciones estéticas con la finalidad de preservar la juventud.

Pensar la muerte del cuerpo y la finitud humana en la Educación Superior implica ser conscientes de que la única oportunidad que tenemos es ésta que hoy nos hace respirar, caminar, sonar y la vivencia de nuestra ausencias. Habrá que mostrar en la educación que lo único que poseemos es la vida y a la vez no la poseemos porque no podemos modificar la historia que hemos heredado, nuestro pasado y condición geográfica-cultural a la que hemos llegado en el momento del nacimiento.

Ese no poder modificar el pasado, nos permite imaginar y construir un mundo, una situación de vida de otro modo, es desde la imposibilidad que surge la posibilidad de formación humana y también de la inhumana, porque en el fondo no estamos satisfechos con nosotros mismos, por eso el ser humano crea y destruye no sólo el espacio físico que habita, también su espacio interior que lo modifica para dar forma a su ser.

Para el filósofo Joan Carles Mèlich, la finitud humana es sinónimo de vida, nunca de muerte, la finitud nos dice que nacemos, vivimos, heredamos, sufrimos, gozamos y tarde o temprano moriremos.

La finitud es una vida que no poseemos del todo por eso nuestra existencia se vuelve angustiante y siempre en deseo constante, por querer postergar el placer que dura un instante como diría Oscar Wilde en el "artista".

Seguimos anclados en una metafísica de lo inmóvil, de lo inmutable, que por más que nos empeñemos no deja de persistir y, esa indudablemente se ve reflejada en no aceptar la finitud del cuerpo, por tal razón se recurre a las cirugías estéticas como una forma de preservar el cuerpo, de no aceptar las inclemencias de cronos, de descubrirnos finitos y negarlo, de desear un no fluir de la carne de permanecer joven siempre.

\section{Bibliografía}

Constante, Alberto. (2014): Escrito en el cuerpo mío, cuerpo extraño. En Á. Xolocotzi, \& R. Gibu, Fenomenología de cuerpo y hermenéutica de la corporeidad (pág. 279). México: Plaza y Valdéz.

Duch, Lluís, \& MÈLICH, Joan Carles. (2005). Escenarios de la corporeidad. Antropología de la vida cotidiana 2/1. Madrid: Trota.

Isaps (2014). Procedures Performed in 2013. Obtenido de www.prnewswire.com/.../lasociedad-internacional-de-cirugia-plastica-est... http://www.isaps.org/Media/Default/global-statistics/2014\%20ISAPS\%20Global\%20 Stat\%20Results.pdf

Martínez Ana. (2004). La construcción social del cuerpo en las sociedades contemporaneas. Papers: Revista de sociologia (No 73), 17-152. Recuperado el 05 de 02 de 2015, de http:// ddd.uab.cat/pub/papers/02102862n73/02102862n73p127.pdf

Medina, Federico. El cuerpo en la posmodernidad: la salud, el ejercicio físico y el cuerpo perfecto. Signo y Pensamiento No. 28 (XV), 99-122. Recuperado el 05 de 02 de 2015, de http://revistas.javeriana.edu.co/index.php/signoypensamiento/article/view/3083/2356

Mèlich, Joan Carles. (2002). Filosofía de la finitud. Barcelona: 2002. 
